\title{
Potential harms of proton pump inhibitor therapy: rare adverse effects of commonly used drugs
}

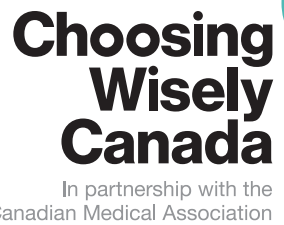
\section{(2)}

Canadian Medical Association

\author{
Amine Benmassaoud MD, Emily G. McDonald MD, Todd C. Lee MD MPH
}

$\mathrm{P}$ roton pump inhibitors (PPIs) are widely prescribed. With more than four million prescriptions in Canada in 2010, esomeprazole became the sixth most commonly prescribed drug in the country. ${ }^{1}$ In the United States, the situation is similar, with more than 15 million patients prescribed PPIs in $2013,{ }^{2}$ at an estimated cost of US $\$ 79$ billion between 2007 and 2011. Use may be even more common, because omeprazole has been approved in the US and Canada for short-term over-the-counter use.

In general, PPIs are safe and have several well-established and evidence-based indications (Appendix 1, available at www.cmaj.ca/lookup/ suppl/doi:10.1503/cmaj.150570/-/DC1). There are many patients, including older adults taking concomitant nonsteroidal anti-inflammatory drugs, steroids or antiplatelet agents, who require long-term prophylaxis with PPIs to decrease their risk of gastrointestinal hemorrhage. However, because PPIs are generally well tolerated, they have been increasingly prescribed for common gastrointestinal symptoms beyond evidence-based indications. Furthermore, as suggested by the Canadian Association of Gastroenterology, ${ }^{4}$ many patients receive long-term PPI therapy and can benefit from periodic reassessment. ${ }^{5}$

Proton pump inhibitors are associated with a number of rare but potentially serious adverse effects. These uncommon effects become highly relevant when considering the tens of millions of patients who take PPIs worldwide. Recognizing some of these harms, the US Food and Drug Administration (FDA) and Health Canada have issued safety advisories regarding the use of PPIs related to Clostridium difficile, fracture risk and profound hypomagnesemia. ${ }^{6-9}$

In this review, we present the potential harms that should be considered when physicians and patients weigh the risks and benefits of starting or continuing long-term PPI therapy (Box 1). The available evidence for the potential harms of PPIs comprises observational studies. As is usual with such studies that identify rare events, association is shown, but causation cannot be proven. Even the best observational studies have a risk of bias owing to residual confounding or other methodologic issues. Nonetheless, it remains prudent to follow Health Canada's advice that "PPIs should be prescribed at the lowest dose and shortest duration of therapy appropriate to the condition being treated." 9 In keeping with the tenets of the Choosing Wisely Canada campaign (Box 2), ${ }^{4}$ new PPI prescriptions ought to be for evidence-based indications, continuous PPI use should be re-evaluated regularly, and patients should be counselled on possible complications when contemplating long-term therapy.

For this review, we have divided the potential harms into three types: drug interactions, noninfectious complications and infectious complications. Where possible, we have included the estimated number needed to harm (NNH). Although not the focus of the review, Appendix 1 provides evidence-based indications for PPI initiation as well as common reasons why the treatment is prescribed without supporting evidence.

\section{Which drugs reportedly interact with PPIs?}

\section{Clopidogrel}

Perhaps the most highly debated drug-drug interaction is that of PPIs and clopidogrel. A population-based study involving 13636 patients
Competing interests: None declared.

This article has been peer reviewed.

Correspondence to: Todd Lee, todd.lee@mcgill.ca

CMAJ 2016. DOI:10.1503 /cmaj.150570

\section{- Ker poInTs}

- Proton pump inhibitors (PPIs) are the most widely prescribed class of gastrointestinal drugs.

- These drugs should be prescribed at the lowest dose and for the shortest duration that is clinically indicated.

- The use of and indication for PPI treatment should be frequently reassessed in clinical practice.

- A growing body of observational evidence associates long-term PPI use with serious adverse effects, including hypomagnesemia, osteoporotic fracture and Clostridium difficile-associated diarrhea.

- Physicians and patients should balance the potential harms of PPI use against the expected benefits. 
who received clopidogrel after myocardial infarction showed that concurrent use of omeprazole was associated with an increased risk of recurrent myocardial infarction within 90 days after the index event (odds ratio [OR] 1.27, 95\% confidence interval [CI] 1.03-1.57); the association was not seen with pantoprazole (OR 1.02, 95\% CI 0.70-1.47). ${ }^{10} \mathrm{~A}$ systematic review and meta-analysis of 25 studies involving 159138 patients showed that concurrent use of PPIs and clopidogrel was associated with a $29 \%$ increased relative risk of combined major cardiovascular events (95\% CI 15\%-45\%) and a $31 \%$ increased relative risk of myocardial infarction $(95 \% \mathrm{CI}$ $12 \%-15 \%$ ), without an influence on mortality (risk ratio 1.04, 95\% CI 0.93-1.16). ${ }^{11}$

In contrast, a within-person case-control study involving 24471 patients showed that PPI use was associated with an increased risk of death or incident myocardial infarction in traditional cohort analysis (hazard ratio [HR] 1.37, 95\% CI 1.27-1.48); however, the investigators found no association when they compared individual patients at times when they were using PPIs with times when they were not (rate ratio $0.75,95 \%$ CI $0.55-1.01) .{ }^{12}$ The authors suggest this indicates residual confounding in the traditional analyses. Furthermore, the Clopidogrel with or without Omeprazole in Coronary Artery Disease (COGENT) trial, a randomized, placebo-controlled, double-blind study, evaluated the combination of acetylsalicylic acid, clopidogrel and omeprazole (a proprietary combination

\section{Box 1: Evidence used in this review}

We used national guidelines from the Canadian Association of

Gastroenterology, the American College of Gastroenterology and the American Association for the Study of Liver Diseases to identify guideline- and evidencebased indications for the use of PPIs and the recommended duration of therapy. We searched PubMed using the following terms: "proton pump inhibitor," "PPI," "safety," "side-effects," "adverse events" and selected randomized control trials, observational studies, systematic reviews and meta-analyses. Other relevant articles were manually retrieved from the reference lists of selected articles. Health Canada and US Food and Drug Administration advisories were also searched for "Proton Pump Inhibitors."

Box 2: Choosing Wisely Canada recommendation on proton pump inhibitor (PPI) therapy ${ }^{4}$

Don't maintain long-term PPI therapy for gastrointestinal symptoms without an attempt to stop or reduce PPI at least once per year in most patients

- PPIs are effective drugs for the treatment of gastroesophageal reflux disease (GERD). Patients should always be prescribed the lowest dose that manages their symptoms. Even though GERD is often a chronic condition, over time the disease may not require acid suppression, and it is important that patients do not take drugs that are no longer necessary. For this reason, patients should try stopping their acidsuppressive therapy at least once per year; patients with Barrett's esophagus, Los Angeles grade D esophagitis and gastrointestinal bleeding would be exempt from this. tablet in which clopidogrel and omeprazole were released at different times) in patients with an indication for dual antiplatelet therapy. ${ }^{13} \mathrm{Al}-$ though the trial showed that omeprazole prevented overt upper gastrointestinal bleeding (number needed to treat $=200$ ), an association between PPI use and incident myocardial infarction was not found. Nonetheless, the authors concluded that they "could not exclude a clinically meaningful difference in cardiovascular events due to omeprazole."

The debate now centres on whether PPI use is really a marker for an at-risk population (confounding by indication) rather than causally associated with myocardial infarction. Regardless, the FDA suggests to "avoid concomitant use of esomeprazole/omeprazole with clopidogrel."14 For patients who require clopidogrel and ongoing PPI therapy, one could consider other PPIs.

\section{Other medications}

Therapeutic levels of numerous other drugs have been shown both in vitro and in vivo to be influenced by PPI use. Studies have shown that omeprazole carries a considerable potential for drug interactions because of its high affinity for cytochrome P450 2C19 and a moderate affinity for cytochrome P450 3A4. ${ }^{15}$ Other PPIs are believed to have less of an affinity, and interactions are not as potent. Medications such as thyroid hormone replacement drugs, chemotherapy drugs (e.g., methotrexate ${ }^{16}$ ), antifungals and antiretroviral agents may be subject to interaction. The concurrent use of PPIs and certain antiretroviral agents may lead to inadequate drug exposure if the interactions are not properly managed. ${ }^{17}$

\section{What are the most important noninfectious adverse events?}

\section{Rebound hyperacidity}

In two randomized controlled trials (RCTs) involving healthy volunteers given four to eight weeks of PPI therapy, ${ }^{18,19}$ dyspepsia occurred in $20 \%$ to $44 \%$ of participants after discontinuation of the PPI and was associated with elevated levels of gastrin and chromogrammin A. This rebound acid hypersecretion may require a tapering off of PPIs in patients who have been on long-term therapy.

\section{Malabsorption of vitamin $\mathrm{B}_{12}$, iron and magnesium}

By altering intragastric $\mathrm{pH}$ levels, PPIs decrease the absorption of vitamin $\mathrm{B}_{12}$ and nonheme iron. A systematic review of observational studies suggested that long-term use of PPIs for more 
than two years is associated with an increased risk of vitamin $\mathrm{B}_{12}$ deficiency (HR $1.83,95 \% \mathrm{CI}$ 1.36-2.46). ${ }^{20}$ With a $10 \%$ estimated baseline risk of vitamin $\mathrm{B}_{12}$ deficiency in older patients, the $\mathrm{NNH}$ for one year of use would be four patients. ${ }^{21}$ No recommendations exist regarding testing for vitamin $\mathrm{B}_{12}$ deficiency in older patients receiving long-term PPI therapy; however, judicious use in high-risk patients is reasonable.

One study of the impact of PPIs on iron absorption has shown that response to oral iron replacement therapy after two months of PPI therapy is reduced in select patients taking PPIs who have no evident source of blood loss. ${ }^{22}$ Another retrospective cohort study has shown that patients taking PPIs have a decreased hemoglobin level and mean corpuscular volume. ${ }^{23}$

Use of PPIs has been associated with an increased risk of severe hypomagnesemia among community-dwelling patients (OR 3.79, 95\% CI 2.99-4.82; NNH = 73). ${ }^{24}$ Hypomagnesemia is most common in patients who have taken PPIs for more than five years. ${ }^{25}$ Severe hypomagnesemia can cause serious adverse events, including tetany, seizures and arrhythmias. Consequently, the FDA has recommended that at-risk cardiac patients requiring ongoing PPI use have their magnesium level verified periodically. ${ }^{26}$

\section{Osteoporosis}

Several meta-analyses and systematic reviews based on observational data have shown an association between recent and chronic PPI use and the risk of fractures in both men and women. ${ }^{27,28}$ In contrast, this association has not been shown with use of histamine-2 receptor antagonists. ${ }^{28}$ Assuming a baseline risk of 1.5 per 1000 patientyears for hip fractures and 6 per 1000 patientyears for vertebral fractures, the $\mathrm{NNH}$ would be 2672 and 337, respectively. ${ }^{29}$ It is postulated that PPIs reduce the oral bioavailability of calcium and that hypergastrinemia and mild hypomagnesemia stimulate parathyroid hormone production leading to increased bone resorption. Another hypothesis is that PPIs inhibit osteoclast proton pumps, leading to increased osteoclast activity and direct alteration of bone metabolism. ${ }^{30}$

\section{Acute interstitial nephritis}

A prospective multicentre study from France of drug-induced acute interstitial nephritis and a retrospective study from the US determined that PPIs were the culprit in $16.7 \%$ and $14 \%$ of cases, respectively. ${ }^{31,32}$ A nationwide nested casecontrol study from New Zealand estimated that, for every 100000 current PPI users more than 60 years of age, there were about 20 cases of acute interstitial nephritis per year $(\mathrm{NNH}=$
5000). ${ }^{33}$ The incidence of this adverse event is low; therefore, a high index of suspicion is required to make the diagnosis and stop the offending medication.

\section{Dementia and functional decline}

An observational study of data derived from the German Study on Aging, Cognition and Dementia in Primary Care Patients $(n=3076)$ showed that PPI use was associated with an increased incidence of any dementia (HR 1.38, 95\% CI $1.04-1.83 ; p=0.02$ ) and specifically Alzheimer dementia (HR 1.44; 95\%CI 1.01-2.06) after adjustment for potential confounding factors. ${ }^{34}$ Two hypotheses exist for the possible mechanism. First, lansoprazole has been shown to enhance production of amyloid $\beta$ protein, which is implicated in the pathogenesis of Alzheimer disease. ${ }^{35}$ Second, gastrin-releasing peptide is elevated in PPI users and has been shown to modulate brain functions related to stress and anxiety.

In addition to dementia, PPI use was also associated, after adjustment, with increased functional impairment (OR 2.44, 95\% CI 1.36$4.41 ; \mathrm{NNH}=15$ ) and mortality (HR 1.51, 95\% CI 1.03-2.77) in frail older patients discharged from hospital with a PPI prescription. ${ }^{36,37}$

\section{What are the most important infectious complications?}

\section{Clostridium difficile-associated diarrhea and other enteric infections}

Clostridium difficile-associated diarrhea causes substantial morbidity and mortality. A large meta-analysis involving 23 studies and 272636 patients from around the world showed that PPI use was associated with an increased relative risk of $C$. difficile by as much as $69 \%$ (risk ratio $1.69,95 \%$ CI 1.40-1.97). ${ }^{38}$ There was no significant heterogeneity between the studies included, and after a conservative adjustment for potential publication bias, the association remained significant (risk ratio $1.26,95 \% \mathrm{CI}$ 1.03-2.24). The NNH among communitydwelling patients with one year of PPI use has been estimated to be 3925 , decreasing to 50 at 14 days among patients in hospital receiving antibiotics. ${ }^{39}$ Use of PPIs has also been shown to increase the risk of recurrence of $C$. difficile (HR 1.5, 95\% CI 1.1-2.0), and yet few patients have their PPI stopped during an episode of C. difficile despite nearly $50 \%$ of ongoing use being potentially inappropriate. ${ }^{40}$

Use of PPIs is associated with an increased 
risk of other bacterial enteric infections, as was shown in a meta-analysis of five studies (OR 3.33, 95\% CI 1.84-6.02). ${ }^{41}$ The pathogens most often isolated were Campylobacter and Salmonella species. There is also limited and theoretical evidence that PPI use may be related to traveller's diarrhea and to infections caused by Vibrio cholerae and Listeria monocytogenes. ${ }^{42}$

\section{Spontaneous bacterial peritonitis}

Spontaneous bacterial peritonitis can occur in patients with cirrhosis and ascites and is an important cause of morbidity and mortality. Bacterial translocation is thought to play a key role in its pathogenesis and is hypothesized to increase in patients receiving PPIs. Two meta-analyses, involving 772 and 3815 patients, respectively, showed that the odds of spontaneous peritonitis were increased two- to threefold among people taking PPIs ( $\mathrm{NNH}=9$ ), without significant evidence of heterogeneity. ${ }^{43,44}$ Patients in whom peritonitis develops frequently have no clear indication for continued PPI use. ${ }^{45}$ Therefore, in accordance with the American Association for the Study of Liver Diseases guidelines, ${ }^{46}$ PPIs should be used with caution in patients with cirrhosis and be reserved for an appropriate duration of therapy in patients with peptic ulcer disease, or for a short period following esophageal variceal ligation. ${ }^{1}$

\section{Pneumonia}

Many studies have tried to characterize the association between PPIs and the risk of both hospitaland community-acquired pneumonia. Herzig and colleagues $^{47}$ performed a prospective cohort study and identified PPI use as a risk factor for hospitalacquired pneumonia (OR 1.3, 95\% CI 1.1-1.4; $\mathrm{NNH}=111)$. A meta-analysis that included 23 RCTs and 8 nonrandomized studies showed that PPIs were associated with an increased risk of all-cause pneumonia in a random-effects model to correct for heterogeneity (OR 1.27, 95\% CI 1.111.46). ${ }^{48}$ The risk was higher for communityacquired pneumonia (OR 1.34, 95\% CI 1.141.57), was highest within 7 days after the start of PPI use (OR 3.96, 95\% CI 2.86-5.45) and persisted up to 180 days after the start of treatment (OR 1.36, 95\% CI 1.05-1.78).

One important limitation of these studies is that they did not adjust for gastresophageal reflux disease, which itself may be associated with both PPI use and pneumonia. Using a database of eight separate cohort studies involving patients 40 years or older who were new users of nonsteroidal anti-inflammatory drugs, Filion and colleagues $^{49}$ showed that PPIs did not increase the risk of hospital admission for community- acquired pneumonia in a fixed-effect metaanalytic model. The authors concluded that the association between PPIs and pneumonia may constitute a protopathic bias. Nevertheless, pneumonia remains a frequent cause of morbidity, hospital admission and mortality, and therefore it is prudent to minimize any additional risk of pneumonia by avoiding inappropriate PPI use.

\section{How can inappropriate PPI use be avoided or stopped?}

Several strategies have been developed to minimize PPI use; however, larger studies are required to determine their effectiveness. One strategy paired a 20-minute educational session on the benefits and harms of PPI use with a Webbased tool cueing medical residents to reassess the appropriateness of PPI prescriptions for medical inpatients. ${ }^{5} \mathrm{~A}$ total of $49 \%$ of patients without a clear indication for treatment had their PPI stopped before hospital discharge. Another strategy involved a nurse-led dyspepsia clinic in which a nursing team developed action plans with patients to stop unnecessary PPI use..$^{50}$ At three months, $64 \%$ of the 157 patients had stopped their PPI and another $30 \%$ were taking a reduced dose. Patients who have been taking a PPI at high dose for prolonged durations may experience rebound hyperacidity, and a tapering regimen or step-down to an histamine-2 receptor blocker may help offset these symptoms.

Before prescribing a new PPI, physicians may want to consider whether the patient has an evidence-based indication for the treatment. In Appendix 1 , we provide several evidence-based indications for continuous PPI therapy, as well as some common indications for which PPI treatment is often started but is not supported by the available evidence. For patients who have symptoms of gastresophageal reflux disease, a trial of nonpharmacologic interventions (e.g., avoiding large meals before bedtime, and decreasing caffeine and alcohol consumption) should be considered. Alternatively, a histamine-2 recepter blocker or over-the-counter antacids could be tried before prescribing the most potent available treatment. In patients who are prescribed a PPI, the use should not be indefinite without regular attempts to taper when symptoms are controlled for three months.

By avoiding use outside of the evidence base, maximizing lifestyle interventions and regularly reassessing the indication for long-term PPI use, physicians can minimize PPI exposure and consequently the risk of rare, but important, adverse effects. 


\section{Box 3: Gaps in knowledge}

- There is an important need to identify efficient methods to limit inappropriate prescribing of proton pump inhibitors (PPIs) in clinical practice and to identify deprescribing regimens.

- Direct comparison studies with costeffectiveness analyses of gastroprotective strategies using histamine-2 receptor antagonists and PPIs are needed for stress ulcer prophylaxis in the intensive care unit, for nonsteroidal anti-inflammatory drug therapy with other risk factors and for dual antiplatelet therapy.

- The benefit of PPI therapy for functional dyspepsia or other nonspecific gastrointestinal symptoms needs to be clarified, because many patients will receive a PPI for such indications potentially without benefit.

\section{Conclusion}

The main action of PPIs is a pronounced and long-lasting effect on gastric acid production, which makes this class of drugs a highly effective treatment option for various acid-related disorders. However, their use has become very common and has expanded beyond the evidence base. This has led to increased drug costs and an evolving understanding of the adverse events associated with long-term use. Although gaps in knowledge remain (Box 3), we believe that Health Canada's advice, that PPIs should be prescribed at the lowest dose and for the shortest duration of therapy appropriate to the condition being treated, reflects best practice and follows the tenets of the Choosing Wisely Canada campaign (Box 2). ${ }^{4}$ We encourage patients and their physicians to have regular discussions about the risks and benefits of PPI therapy and to use this review as a reference for shared decision-making.

\section{References}

1. Institute for Healthcare Informatics: pharmaceutical trends; top 50 dispensed medications in Canada, 2010. IMS Institute for Healthcare Informatics; 2011. Available: www.imshealth.com/ deployedfiles/ims/Global/North America/Canada/Home Page Content/Pharma Trends/Top50Dispensed_En_11.pdf (accessed 2015 Oct. 30).

2. Medicine use and shifting costs of healthcare: a review of the use of medicines in the United States in 2013. IMS Institute for Healthcare Informatics; 2014. Available: www.imshealth.com/ deployedfiles/imshealth/Global/Content/Corporate/IMS Health Institute/Reports/Secure/IIHI_US_Use_of_Meds_for_2013.pdf (accessed 2014 Sept. 26).

3. Johansen ME, Huerta TR, Richardson CR. National use of proton pump inhibitors from 2007 to 2011. JAMA Intern Med 2014; 174:1856-8.

4. Canadian Association of Gastroenterology: Five things physicians and patients should question. Toronto: Choosing Wisely Canada; 2014. Available: www.choosingwiselycanada.org/recommendations /gastroenterology-2/2014 (accessed 2015 Aug. 4).

5. McDonald EG, Jones J, Green L, et al. Reduction of inappropriate exit prescriptions for proton pump inhibitors: a before-after study using education paired with a Web-based quality-improvement tool. J Hosp Med 2015;10:281-6.
6. FDA Drug Safety Communication: Possible increased risk of fractures of the hip, wrist, and spine with the use of proton pump inhibitors. Silver Spring (MD): US Food and Drug Administration; 2012. Available: www.fda.gov/Drugs/DrugSafety/Postmarket DrugSafetyInformationforPatientsandProviders/ucm 213206.htm (accessed 2015 Oct. 30).

7. FDA drug safety communication: Clostridium difficileassociated diarrhea can be associated with stomach acid drugs known as proton pump inhibitors (PPIs). Silver Spring (MD): US Food and Drug Administration; 2012. Available: www.fda gov/drugs/drugsafety/ucm290510.htm (accessed 2015 Oct. 30).

8. Proton pump inhibitors (antacids): possible risk of Clostridium difficile-associated diarrhea. Ottawa: Health Canada; 2012. Available: www.healthycanadians.gc.ca/recall-alert-rappel-avis/ hc-sc/2012/13651a-eng.php (accessed 2015 Oct. 30).

9. Proton pump inhibitors: hypomagnesemia accompanied by hypocalcemia and hypokalemia. Can Adverse Reaction Newsl 2011; 21(3):1-2.

10. Juurlink DN, Gomes T, Ko DT, et al. A population-based study of the drug interaction between proton pump inhibitors and clopidogrel. CMAJ 2009;180:713-8

11. Siller-Matula JM, Jilma B, Schrör K, et al. Effect of proton pump inhibitors on clinical outcome in patients treated with clopidogrel: a systematic review and meta-analysis. J Thromb Haemost 2010;8:2624-41.

12. Douglas IJ, Evans SJW, Hingorani AD, et al. Clopidogrel and interaction with proton pump inhibitors: comparison between cohort and within person study designs. BMJ 2012;345:e4388.

13. Bhatt DL, Cryer BL, Contant CF, et al. Clopidogrel with or without omeprazole in coronary artery disease. $N$ Engl $\mathrm{J} \mathrm{Med}$ 2010;363:1909-17.

14. Interaction between esomeprazole/omeprazole and clopidogrel label change. Silver Spring (MD): US Food and Drug Administration; 2012.

15. Wedemeyer RS, Blume H. Pharmacokinetic drug interaction profiles of proton pump inhibitors: an update. Drug Saf 2014;37: 201-11.

16. New safety information: Interaction of proton pump inhibitors (PPIs) with methotrexate. Ottawa: Health Canada; 2012. Available: www.healthycanadians.gc.ca/recall-alert-rappel-avis/ hc-sc/2012/15076a-eng.php (accessed 2015 July 29).

17. Lewis J, Stott K, Monnery D, et al. Managing potential drugdrug interactions between gastric acid-reducing agents and antiretroviral therapy: experience from a large HIV-positive cohort. Int J STD AIDS 2015 Feb. 25 [Epub ahead of print].

18. Reimer C, Sondergaard B, Hilsted L, Bytzer P. Proton-pump inhibitor therapy induces acid-related symptoms in healthy volunteers after withdrawal of therapy. Gastroenterology 2009;137:80-7.

19. Niklasson A, Lindstrom L, Simren M, et al. Dyspeptic symptom development after discontinuation of a proton pump inhibitor: a double-blind placebo-controlled trial. Am J Gastroenterol 2010; 105:1531-7.

20. Jung SB, Nagaraja V, Kapur A, et al. The association between vita$\min B_{12}$ deficiency and long-term use of acid lowering agents: a systematic review and meta-analysis. Intern Med J 2015;45:409-16.

21. Valuck RJ, Ruscin JM. A case-control study on adverse effects: $\mathrm{H}_{2}$ blocker or proton pump inhibitor use and risk of vitamin $\mathrm{B}_{12}$ deficiency in older adults. J Clin Epidemiol 2004;57:422-8.

22. Ajmera AV, Shastri GS, Gajera MJ, et al. Suboptimal response to ferrous sulfate in iron-deficient patients taking omeprazole. Am J Ther 2012;19:185-9.

23. Sarzynski E, Puttarajappa C, Xie Y, et al. Association between proton pump inhibitor use and anemia: a retrospective cohort study. Dig Dis Sci 2011;56:2349-53.

24. Markovits N, Loebstein R, Halkin H, et al. The association of proton pump inhibitors and hypomagnesemia in the community setting. J Clin Pharmacol 2014;54:889-95.

25. Cundy T, Mackay J. Proton pump inhibitors and severe hypomagnesaemia. Curr Opin Gastroenterol 2011;27:180-5.

26. FDA drug safety communication: Low magnesium levels can be associated with long-term use of proton pump inhibitor drugs (PPIs). Silver Spring (MD): US Food and Drug Administration; 2011. Available: www.fda.gov/Drugs/DrugSafety/ucm245011.htm (accessed 2015 Oct. 23).

27. Yu EW, Bauer SR, Bain PA, et al. Proton pump inhibitors and risk of fractures: a meta-analysis of 11 international studies. Am J Med 2011;124:519-26.

28. Eom CS, Park SM, Myung SK, et al. Use of acid-suppressive drugs and risk of fracture: a meta-analysis of observational studies. Ann Fam Med 2011;9:257-67.

29. Ngamruengphong S, Leontiadis GI, Radhi S, et al. Proton pump inhibitors and risk of fracture: a systematic review and metaanalysis of observational studies. Am J Gastroenterol 2011;106: 1209-18, quiz 19. 
30. Jo Y, Park E, Ahn SB, et al. A proton pump inhibitor's effect on bone metabolism mediated byosteoclast action in old age: a prospective randomized study. Gut Liver 2015;9:607-14

31. Leven C, Hudier L, Picard S, et al. Prospective study of druginduced interstitial nephritis in eleven French nephrology units [article in French]. Presse Med 2014;43:e369-76.

32. Muriithi AK, Leung N, Valeri AM, et al. Clinical characteristics, causes and outcomes of acute interstitial nephritis in the elderly. Kidney Int 2015;87:458-64.

33. Blank ML, Parkin L, Paul C, et al. A nationwide nested casecontrol study indicates an increased risk of acute interstitial nephritis with proton pump inhibitor use. Kidney Int 2014;86:837-44.

34. Haenisch B, von Holt K, Wiese B, et al. Risk of dementia in elderly patients with the use of proton pump inhibitors. Eur Arch Psychiatry Clin Neurosci 2015;265:419-28.

35. Badiola N, Alcalde V, Pujol A, et al. The proton-pump inhibitor lansoprazole enhances amyloid beta production. PLOS ONE 2013;8:e58837.

36. Corsonello A, Maggio M, Fusco S, et al. Proton pump inhibitors and functional decline in older adults discharged from acute care hospitals. J Am Geriatr Soc 2014;62:1110-5.

37. Maggio M, Corsonello A, Ceda GP, et al. Proton pump inhibitors and risk of 1-year mortality and rehospitalization in older patients discharged from acute care hospitals. JAMA Intern Med 2013;173:518-23

38. Janarthanan S, Ditah I, Adler DG, et al. Clostridium difficileassociated diarrhea and proton pump inhibitor therapy: a metaanalysis. Am J Gastroenterol 2012;107:1001-10.

39. Tleyjeh IM, Bin Abdulhak AA, Riaz M, et al. Association between proton pump inhibitor therapy and Clostridium difficile infection: a contemporary systematic review and meta-analysis. PLOS ONE 2012;7:e50836.

40. McDonald EG, Milligan J, Frenette C, et al. Continuous proton pump inhibitor therapy and the associated risk of recurrent Clostridium difficile infection. JAMA Intern Med 2015;175:784-91.

41. Leonard J, Marshall JK, Moayyedi P. Systematic review of the risk of enteric infection in patients taking acid suppression. Am J Gastroenterol 2007; 102:2047-56, quiz 57.

42. Bavishi C, Dupont HL. Systematic review: the use of proton pump inhibitors and increased susceptibility to enteric infection. Aliment Pharmacol Ther 2011;34:1269-81.

43. Trikudanathan G, Israel J, Cappa J, et al. Association between proton pump inhibitors and spontaneous bacterial peritonitis in cirrhotic patients: a systematic review and meta-analysis. Int $J$ Clin Pract 2011;65:674-8.

44. Deshpande A, Pasupuleti V, Thota P, et al. Acid-suppressive therapy is associated with spontaneous bacterial peritonitis in cirrhotic patients: a meta-analysis. J Gastroenterol Hepatol 2013;28:235-42.

45. Ratelle M, Perreault S, Villeneuve JP, et al. Association between proton pump inhibitor use and spontaneous bacterial peritonitis in cirrhotic patients with ascites. Can J Gastroenterol Hepatol 2014;28:330-4.

46. Runyon BA. Management of adult patients with ascites due to cirrhosis: update 2012. Alexandria (VA): American Association for the Study of Liver Disease; 2012. Available: www.aasld.org/ sites/default/files/guideline_documents/adultascitesenhanced.pdf (accessed 2015 May 10).

47. Herzig SJ, Howell MD, Ngo LH, et al. Acid-suppressive medication use and the risk for hospital-acquired pneumonia. JAMA 2009;301:2120-8

48. Eom CS, Jeon CY, Lim JW, et al. Use of acid-suppressive drugs and risk of pneumonia: a systematic review and meta-analysis. CMAJ 2011;183:310-9.

49. Filion KB, Chateau D, Targownik LE, et al. Proton pump inhibitors and the risk of hospitalisation for community-acquired pneumonia: replicated cohort studies with meta-analysis. Gut 2014;63:552-8.

50. Murie J, Allen J, Simmonds R, et al. Glad you brought it up: a patient-centred programme to reduce proton-pump inhibitor prescribing in general medical practice. Qual Prim Care 2012;20: $141-8$

Affiliations: Division of General Internal Medicine (Benmassaoud, McDonald, Lee), Department of Medicine, McGill University Health Centre; McGill Centre for Quality Improvement (McDonald, Lee), Montréal, Que.

Contributors: Amine Benmassaoud and Emily McDonald provided equal contributions as co-first authors. All of the authors contributed to the revising of the manuscript, approved the final version to be published and agreed to act as guarantors of the work.

CMAJ is collaborating with Choosing Wisely Canada, with support from Health Canada, to publish a series of articles describing how to apply the Choosing Wisely Canada recommendations in clinical practice.

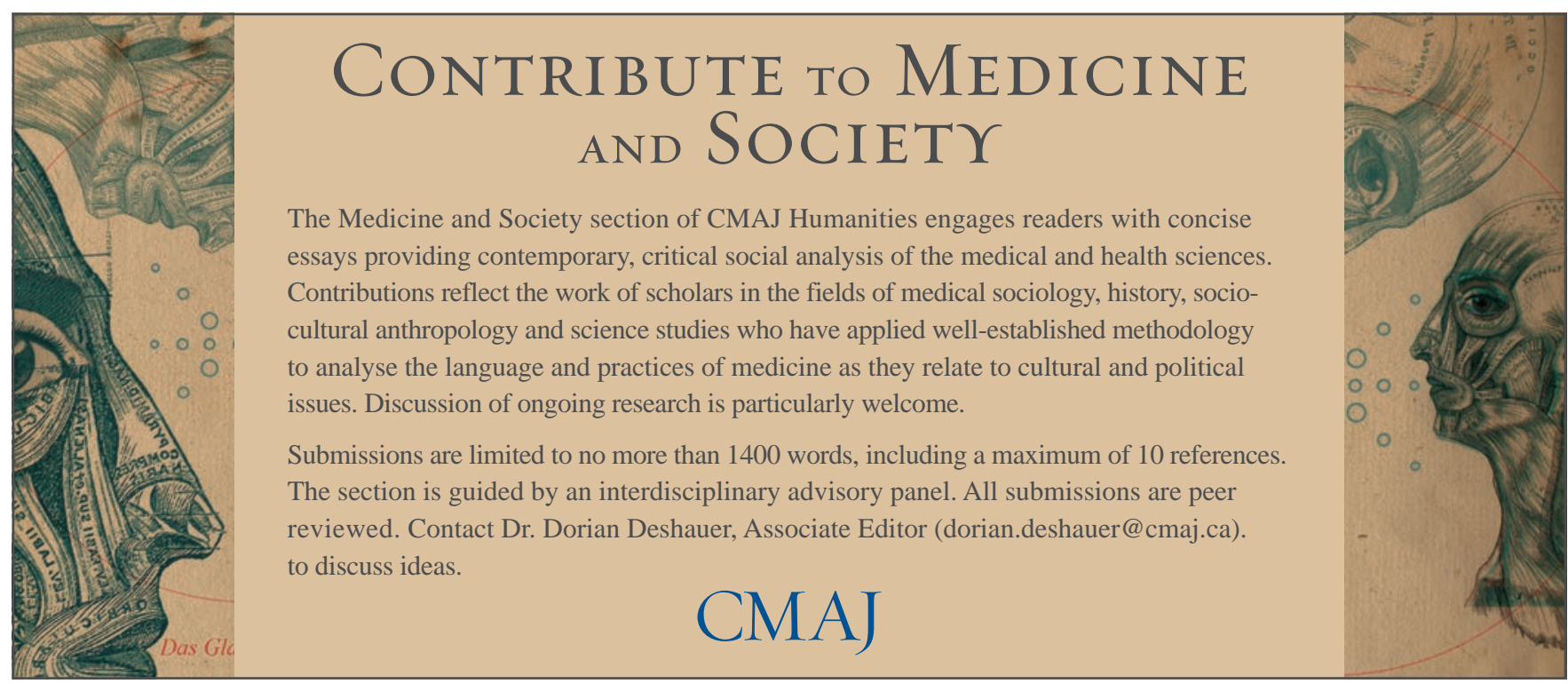

